\title{
Examining the Factors Affecting the Evaluation and Adoption of IT Investments in Pharmaceutical Organizations
}

\author{
Chad Lin \\ Centre for Behavioural Research in Cancer Control, Curtin University \\ Curtin Health Research Campus, 10 Selby Street, Shenton Park, WA 6008, Australia \\ elin123au@yahoo.com.au
}

\begin{abstract}
Information technology (IT) holds potential for transforming business practices in important ways. For example, it can assist in setting up an infrastructure which supports complex, multiparty trading and transactions among pharmaceutical manufacturers, wholesalers, hospitals, pharmacies, medical supply importers and exporters, and other players in the healthcare system. Effective use of IT can also help these healthcare organizations to reduce costs in supplying and distributing medicines and other medical-related products to the general public. However, despite high expectations for realizing the benefits of IT investments in pharmaceutical supply chain, issues surrounding its evaluation and adoption remain poorly understood and relatively under-researched. This paper presents case study findings on key evaluation and management issues in adopting and utilizing IT investments on seven Australian pharmaceutical organizations. The main objectives of this study are to: (1) examine the IT investment evaluation and benefits realization practices and processes in the pharmaceutical organizations; and (2) identify key IT investment evaluation and adoption issues and challenges within the pharmaceutical supply chain. A key contribution of this paper is the identification and examination of key issues and challenges faced by the pharmaceutical organizations undertaking IT and supply chain systems.
\end{abstract}

Keywords: IT evaluation, pharmaceutical organizations, healthcare, IT investments

\section{Introduction}

The pharmaceutical industry is one of the most research-oriented and IT-intensive sectors of the Australian economy. It is also one of Australia's leading exporters, totaling more than US\$3.8 billion in 20102011 and the industry directly employs around 41,000 people. ${ }^{1}$ The industry also contributes over US\$6 billion annually to the Australian economy. ${ }^{1}$ IDC has estimated that IT spending by the Australian healthcare and pharmaceutical organizations is likely to reach US\$2.16 billion by $2013 .^{2}$ Supply chain systems in healthcare and pharmaceutical industries have been known to be much more complicated than those in other industries. ${ }^{3}$ The use of IT by the Australian pharmaceutical supply chain can potentially assist in setting up an infrastructure which supports complex, multiparty trading and transactions among pharmaceutical manufacturers, wholesalers, hospitals, pharmacies, and medical supply traders.

The use of appropriate IT can potentially assist these pharmaceutical organizations in realizing the savings in producing, marketing, and distributing medical supplies as well as in reducing the supply chain costs. For example, the use of video-conferencing equipment enables pharmaceutical organizations to market and supply their products more effectively via online detailing by answering queries from GPs or other medical professionals in real time and by providing drug information on demand. ${ }^{4}$ However, despite high expectations for realizing the benefits of IT investments in pharmaceutical supply chain, issues surrounding its 
evaluation and adoption remain poorly understood and relatively under-researched. There are significant gaps in our understanding of pharmaceutical supply chain and the key issues affecting the use of IT within the industry. ${ }^{5,6}$ Moreover, there have been concerns during the last decade by many in the pharmaceutical industry that escalating costs in manufacturing and supplying the requisite medicines to the Australian population are impeding the industry growth. ${ }^{7}$ Furthermore, the supply chain within the industry is often overly complicated due to internal (e.g. competition) and external (e.g. regulation) factors. Therefore, the main objectives of this study are to: (1) examine the IT investment evaluation and benefits realization practices and processes in the pharmaceutical organizations; and (2) identify key IT investment evaluation and adoption issues and challenges within the pharmaceutical supply chain. The results will hopefully guide senior executives in these organizations to develop their own approaches or strategies to manage the opportunities and threats that exist in the pharmaceutical supply chain.

\section{Pharmaceutical Supply Chain Systems}

Supply and procurement-related costs are significant and can represent about $30 \%$ of total hospital expenditure. ${ }^{3}$ In the past, EDI systems have been used widely by pharmaceutical organizations to conduct business and these systems often link customers to only one pharmaceutical supplier. These proprietary EDI systems are expensive and time consuming to develop and maintain. Driven by concerns about increasing supply and procurement costs in the industry, several IT initiatives and entities have been launched by the government and the pharmaceutical industry during the last decade to develop better ways of ordering and procuring medical and pharmaceutical supplies electronically within the Australian pharmaceutical industry. IT pharmaceutical projects such as Project Electronic Commerce and Communication and the Pharmaceutical Extranet Gateway in 1996, National Supply Chain Reform Task Force in 2000, National EHealth Transition Authority in 2004, Queensland Health pilot e-Procurement project in 2004, and GS1Locatenet GLN Directory for e-health supply chain in 2010 are some of the IT initiatives that have been implemented to link pharmaceutical manufacturers, wholesalers and other medical suppliers with hospitals and pharmacies.
These IT initiatives have been implemented to reduce and manage the overall supply chain and procurement costs to the healthcare industry. Therefore, it is in pharmaceutical organizations' interest to identify key evaluation and management issues in adopting and utilizing IT investments in order to define the appropriate role for supply chain systems in the organization. Difficulty in dealing with costs and benefits are some of the major problems in IT adoption. ${ }^{8,9}$ Senior executives not only wish to evaluate their IT investments in terms of business measures and productivity gains but also want to find out where value has arisen in many areas of the organization as well as how to operate and manage the IT systems and supply chain. $^{10,11}$

\section{IT Investment Evaluation}

Gaining business value from, and justifying current investment in IT in healthcare are often identified as the most critical but difficult management issues in many countries including Australia., ${ }^{9,12}$ Yet, while IT is seen as a competitive weapon there is still a lack of understanding of the impact of the proper IT investment evaluation and benefits realization processes. $^{13,14}$ Despite the high expectations for the value from the increasing number of IT in healthcare being developed, its evaluation issues and processes remain poorly understood. ${ }^{9,12}$ The difficulties in measuring benefits and costs are often the cause for uncertainty about the expected benefits of IT investment and hence are the major constraints to IT investments (Lin et al., 2011b). ${ }^{15}$

Despite the availability of many evaluation methodologies, and the increased spending on IT, many organizations still do not understand the importance of the investment evaluation processes. ${ }^{16,17}$ Consequently, the inability of many organizations to assimilate and apply IT both, inter-and intra-organizationally is resulting in missed opportunities and a lack of business benefits. The difficulties associated with determining the benefits and costs of IT are deemed to be the major constraint to investment justification. ${ }^{8,18}$

\section{IT Investment Benefits Realization}

The difficulties in evaluating benefits are often the cause for uncertainty about the expected benefits of IT investment. ${ }^{19,20}$ In addition, organizations have come to realize that it is increasingly difficult to justify the costs 
surrounding the procurement, development and adoption of IT investments. ${ }^{9}$ Hence, evaluation is often ignored or carried out inefficiently or ineffectively because of its elusive and complex nature. ${ }^{19,20,21,22}$ There are many methodologies that can be used to evaluate IT investments and some of the most widely recognized are: Information Economics Approach; ${ }^{23}$ Kobler Unit Framework; ${ }^{17}$ and Multi-object, Multi-criteria Methods. ${ }^{11}$ While IT investment evaluation processes are important for organizations, they are still insufficient in terms of ensuring that the benefits required are realized and delivered to the organization. ${ }^{24}$ Assessing the effective delivery of useful benefits from these services to the business is very difficult. ${ }^{8}$ Benefits realization comprises of a range of management activities designed to ensure that an organization realized the benefits it plans to achieve from an IT investment. ${ }^{11}$ Benefits may be considered as the effect of the changes, i.e. management of changes - the difference between the current and proposed way that work is done. $^{24}$

\section{Issues and Challenges for IT Investment Evaluation and Benefits Realization}

Failure to plan for and, derive the benefits from an IT investment such as IT can have detrimental consequences on organizational performance. ${ }^{14}$ Some of the major problems associated with IT investment evaluation are: $:^{8,25,24}$

- Organizations often fail to measure their IT investments and identify relevant risks, costs, and benefits;

- Traditional financially oriented evaluation methods (e.g. ROI, NPV) can be problematic in measuring IT investments and quantifying relevant benefits and costs;

- Organizations often have neglected to devote appropriate evaluation time and effort to IT investments such as IT as well as to deal with the extended investment time frame. Organizations have failed to understand that IT investments require richer evaluation approaches than mono-dimensional costbenefit analysis;

- The nature of electronic commerce technology makes it harder for organizations to allocate and assign costs and benefits to IT projects, further blurring the lines of capital investment and return from IT spending; and

- It is very difficult to evaluate intangibles and make relationship between IT and profitability explicit.

Indeed, many organizations have found that costs and benefits for IT can be difficult to estimate and control. $^{26,27}$ For instance, many organizations face the difficulties in measuring and monitoring the performance of the specific contribution of inputs in generating outputs. ${ }^{28}$ Moreover, other less quantifiable items such as loyalty, trust, knowledge, brand awareness, relationships, the boundaries of interorganizational networks, value creation and customer satisfaction all makes the evaluation even more difficult. $^{27}$

\section{Research Methodology}

Semi-structured interviews as part of the case study approach were conducted with participants (i.e. IT managers, IT procurement managers, supply chain managers, and system users) from seven Australian pharmaceutical organizations to identify the relevance, importance and relationships of the constructs taken from the literature. The case study method enables the researcher to examine the context of the IT investment evaluation and benefits realization processes and better understand the responses given in the interviews through observation. Semi-structured interviews were conducted to gain a deeper understanding of issues. The data collection at these cases continued until a point of theoretical saturation, which is when the value of an additional interview was considered to be negligible. ${ }^{29}$ The questions asked during the interviews included current practices and norms of managing IT investments, IT investment evaluation and benefits realization issues and challenges, and IT adoption and implementation management issues in the context of the procurement, supply chain, and distribution of goods and services. Multiple data sources were used and included company documents and annual reports. Extensive notes were taken during the interviews and they were later were coded and analyzed. This serves as a method of triangulation of research data and ensures that the questions and answers are properly understood by repeating or rephrasing the questions and through 
paraphrasing the responses back to the interview participants. $^{30}$

Qualitative content analysis by Miles \& Huberman ${ }^{31}$ was then used to analyze the data from the case study. The analysis of the case study results was conducted in a cyclical manner and the results were checked by other experts in the field. The external experts were asked to trace the logical flow of the research study, research questions, case findings and analysis and identification of constructs and thereby identifying any gaps in the chain of evidence. $^{32}$ The findings from these information gathering approaches were analyzed iteratively by the researcher on an individual level, differences reconciled and then a judgment made on each of the major themes. Questions relating to a particular research theme, for example, level of IT investment evaluation methodology usage, were examined as a cluster. Divergent views within the same organization were assessed in terms of the relative strength of the perspective according to the numbers of responses falling in particular categories. This was done as a form of in-case analysis and to develop general explanations and interpretations. ${ }^{29}$ These steps enhance the construct validity, reliability and overall quality of the research. ${ }^{32}$

\section{Research Findings}

A number of key management and evaluation issues and challenges arose from the analysis of case study data and they are presented below.

\subsection{Lack of IT Benefits Realization Methodologies}

All pharmaceutical organizations interviewed stated that they had used at least one informal IT investment evaluation methodology/process to evaluate/assess their IT investments. Less than half of these organizations had adopted some sort of an IT investment benefits realization methodology/process and most of these organizations interviewed believed that these methodologies/processes were effectively adopted. However, only two pharmaceutical organizations were able to produce a benefits delivery plan as part of their IT investment evaluation methodology/process or IT benefits realization methodology/process. In most cases, intangible benefits and costs were omitted from evaluation studies, because they could not be quantified or justified by traditional financial evaluation techniques (e.g. NPV, IRR, ROI). Only those organizations which had adopted both IT investment evaluation methodology/process and IT benefits realization methodology/process had conducted postimplementation reviews. These reviews were often conducted as part of the evaluation methodology/process within six months after the completion of the project. The main purpose of conducting the review was to formally close out the IT projects and to assess whether or not the planned benefits were realized, rather than to improve future IT projects.

\subsection{Organizational IT Infrastructure}

Most responding pharmaceutical organizations did not seem to possess the appropriate and/or flexible hardware, software, and IT staff to undertake the new IT projects such as supply chain systems. Existing IT applications and business processes were not integrated well in most of the organizations interviewed. Weill ${ }^{33}$ classified IT infrastructure and capabilities into the following three components: (1) shared IT components; (2) IT human/management competence; and (3) shared technological services. Half of the organizations interviewed had acquired appropriate and sufficient hardware and software to maintain their IT and supply chain systems. In terms of the IT human/management competence component, most organizations interviewed revealed that they had possessed sufficient technical managerial skills while less than of them stated that they had appropriate IT planning and management practices to manage their IT and supply chain systems. In terms of the shared technological services, most organizations interviewed stated that their existing IT and supply chain applications and business processes were not integrated well. Most organizations did not possess appropriate shared set of IT applications and business processes to manage their IT and supply chain systems. The results also show a positive relationship between the pharmaceutical organizations which possessed higher level of organizational IT infrastructure and capabilities and the use of both IT investment evaluation and benefits realization methodologies and processes by these organizations. 


\subsection{Lack of User Consultation}

The relevant literature has stressed that there is a direct relationship between user involvement and system success. ${ }^{34}$ However, much of the adoption and use of IT systems by the Australian pharmaceutical organizations interviewed were generally forced upon the employees by the senior management. Many stakeholders and users within the organizations interviewed said they were not extensively consulted beforehand and were not involved in the designing and adoption of these systems. Those organizations which kept the users and customers in the dark would tend to have low usage for their systems. Moreover, many benefits expected from the adoption of these systems were mainly tailored for the senior managers. Furthermore, there was a positive relationship between organizations which had adopted IT investment evaluation and benefits realization methodologies and those which had extensively consulted with system users before implementing their IT and/or supply chain systems.

\subsection{High Level of Government Regulations and Controls}

The Australian pharmaceutical industry has been subject to the pressures exerted by the government. Growing health spending also puts pressure on Australian Federal and State governments to control the costs of medicine. In Australia, government is the major purchaser of medicine and pharmaceutical supplies. The Pharmaceutical Benefits Pricing Authority and the Department of Health and Aging are able to set prices that pharmaceutical organizations and pharmacies can receive or charge for Pharmaceutical Benefits Scheme (PBS) medicines. This is despite the fact that the pharmaceutical wholesale market has been dominated by about three full-line pharmaceutical organizations (account for approximately 90\% of the market share) (Sweeney, 2007). While purchasing decisions are often made by patients on the advice of their GPs, most prescription medicines are purchased under the PBS. In addition, the public hospital pharmaceutical market is also controlled by the State governments via centralized purchasing and tendering guidelines. Hence, pharmaceutical organizations are often under the pressure to reduce costs and comply with both national and international regulations (e.g. bar coding, SarbanesOxley Act), for example, via the effective use of IT and supply chains. Although there is not much pharmaceutical organizations can do about the pricing and regulatory pressure, they need to ensure that their IT systems and supply chain can assist in bringing about all the expected benefits. Those organizations which had adopted IT investment evaluation and benefits realization methodologies appeared to be able to cope with government regulations and control better than those which had not adopted any of the evaluation methodologies.

\subsection{Implementation of Evaluation and Objectives for IT Investment}

It is important for organizations to link their evaluation strategies and objectives with their IT investments. Six out of seven pharmaceutical organizations interviewed indicated that they had a process to ensure that their IT investments were linked to their organizational objectives and strategies. Of those who had this, organizational planning processes and organizational alignment activities were most often used by interview participants to help ensuring that their investments were connected to their organizational objectives and strategies. According to the interview participants, senior IT executives were responsible for defining and formulating strategic goals and strategies for their IT investments. Senior IT executives were also responsible for making ensure that these investments were linked with their organizational objectives and strategies. Although senior IT executives were responsible for preparing and submitting the justification for organizational approval for IT investments, IT managers were usually responsible for evaluating and implementing these investments.

\subsection{Lack of IT Pre-project Justification Process}

The IT pre-project justification process would assist an organization to identify challenges and costs/benefits for a particular IT project. Just over half of the pharmaceutical organizations interviewed believed that their current project justification process failed to identify all available benefits for their IT projects. Most interview participants revealed that intangible benefits were difficult to quantify and identify. All interview participants admitted that they had place more emphasis on getting project approval than on delivering the planned benefits during their pre-project justification process. However, all but one of the pharmaceutical 
organizations interviewed had indicated pilot studies were conducted before the implementing their IT projects. Main reasons for conducting the pilot studies were: (1) to identify and understand potential benefits; (2) to fully evaluate the technology and its costs; and (3) to solicit user requirements.

\subsection{Realization of Planned IT Benefits}

Most of the pharmaceutical organizations interviewed said that they were confident that their IT projects had actually delivered benefits to their organizations. Some of the most mentioned reasons for this were user feedback and company reviews. The interview participants also revealed a number of issues that might undermine confidence - lack of financial resources to operate IT systems, the selection of wrong projects, lack of technical expertise, lack of formal evaluation approaches, lack of clearly defined objectives and strategy, and inability to achieve the intended cost savings. According to the interview participants, the success criteria of the IT systems were often determined through company reviews, meetings, or user feedback. In other cases project delivery "on time, working, to budget" was quoted, rather than measured benefits as a result of changes within the business. All but one of the organizations interviewed indicated that the success criteria were defined before the pre-project justification approval process. The other pharmaceutical organization defined its success criteria just before the actual implementation of its IT project.

\subsection{Linkage between degree of Satisfaction and Use of IT Benefits Realization Methodology}

The findings revealed that those pharmaceutical organizations which had adopted an IT benefits realization methodology or process tend to experience a higher level of user satisfaction with their IT and supply chain systems. Although a great majority of organizations did not think that the adoption of a supply chain system would assist them in establishing stronger link with the suppliers and patients, most indicated that it had somehow enhanced the corporate image of their organizations and, to a certain extent, reduced costs of information gathering. The responding organizations had also stated that factors such as their organizational IT readiness, top management support, perceived time pressure, and user resistance were critical in enhancing their user's degree of satisfaction with the adoption of IT/supply chain systems. Many responding organizations suggested that the degree of satisfaction could be influenced by the amount of spending on IT investments.

\section{Discussion}

Several current evaluation practices and issues for IT investments and supply chain systems by participating pharmaceutical organizations were identified and discussed - lack of IT benefits realization methodologies, lack of proper organizational IT infrastructure and capabilities, lack of user consultation, high level of government regulations and control, implementation of evaluation strategies and objectives for IT investment, lack of IT pre-project justification process, realization of planned IT benefits, and linkage between degree of satisfaction and user of IT benefits realization methodologies. These can potentially assist other pharmaceutical organizations in enhancing the understanding of their IT investment evaluation practices and norms. It is imperative for pharmaceutical organizations to adopt formal IT investment evaluation and benefits realization methodologies/processes in order to assess their IT projects and supply chain systems as well as to realize the planned benefits associated with such systems.

It is also important for the senior executives of the pharmaceutical organizations to carefully examine their current practices and focus their attention on the key management issues and challenges. For example, IT investment evaluation methodology can be used to assess the feasibility of the proposed IT projects and supply chain systems as well as the potential interoperability problems with other existing IT systems or functions before and during the pre-project justification stage. Other behavioral, attitudinal and organizational issues should also not be neglected. From a practical standpoint of view, understanding the reactions of their employees and users toward the newly developed and adopted IT and supply chain systems and their subsequent behavior can help pharmaceutical organizations to devise appropriate intervention strategies and programs to maximize their use and effects on the organizations. 
Moreover, when an IT or supply chain system is being developed, the pharmaceutical organizations should place more emphasis on participation from the key stakeholders. The decision-making process for implementing these IT and supply chain systems must take into account of these key stakeholders' points of view. For example, a better understanding of the stakeholders' requirements may help design better systems, strategies, and programs that are necessary to obtain planned IT benefits. Furthermore, more emphasis should also be given to communication between these stakeholders, vendors, and the senior executives to facilitate the successful adoption and implementation of the system as well as knowledge sharing. Incentives can also be used to encourage a particular behavior (e.g. increased IT or supply chain system usage).

\section{Conclusion and Future Research Directions}

For more than a decade, the Australian government has been trying to establish a workable national e-health system in an effort to create a more integrated IT healthcare system which is linked to the many healthcare providers to better serve patients. The establishment of an effective and standardized pharmaceutical supply chain is one of the key components of the reform and policy. Several pharmaceutical and healthcare IT and supply chain initiatives have been launched by governments at both the Federal and State levels in the past to develop better ways of ordering and procuring medical and pharmaceutical supplies electronically within the Australian pharmaceutical industry. However, despite substantial amount of resources being spent by the government, these initiatives had only achieved limited success. After many government reviews, reports, and initiatives, Australia is still no closer to the realization of a national approach to e-health.

Nevertheless, whatever the benefits for the pharmaceutical industry as a whole, investments in IT do not always result in higher revenues. Due to the limited IT sophistication between pharmaceutical organizations and their distributors, suppliers, and business partners in the past, they are lagging behind the bigger players in other industries in using IT and supply chain to create competitive business networks. These systems can transform industry by shifting business focus from physical stores to the virtual business. It has the potential to create a more level playing field for all industry players. In order to provide their customers and business partners with faster and efficient business transactions, pharmaceutical organizations need to combine their managerial expertise and IT resources in pharmaceutical supply chain to obtain market liquidity and to increase market share. This can assist these pharmaceutical organizations to conduct business with both domestic and overseas customers in a timely and secure fashion.

Finally, while the study makes important contributions to the relevant literature, some limitations in our research need to be acknowledged. First, the choice of variables used in this study may not fully capture the complex nature of the evaluation process of the pharmaceutical organizations. Moreover, the study involved seven pharmaceutical organizations in Australia and the findings are based on the Australian context. It would be interesting to conduct the research in other countries and with different healthcare systems and applications. Furthermore, there is still a lot to be learned in the area of processes and practices of IT investment evaluation and benefits management and it is hoped that better IT adoption and implementation strategies and business processes may be developed by pharmaceutical organizations.

\section{References}

1. DIISR Australian Pharmaceuticals Industry Data Card 2011, Department of Innovation, Industry, Science \& Research, Canberra, Australia (2013).

2. J. A. Chiew, Kim, A., Wang, G. J., \& Martin, M. Business Strategy: Health Insights Country Report for Australia, IDC Health Insight, March, USA (2010).

3. E.S. Scheller, and Smeltzer, L. R. Strategic Management of the Health Care Supply Chain, $1^{\text {st }}$ Ed., Wiley, CA, USA (2006).

4. J. Houghton Information Technology \& the Revolution in Healthcare, Pharmaceutical Industry Project - Equity, Sustainability \& Industry Development Working Paper Series No. 4, Centre for Strategic Economic Studies, Victoria University of Technology, Australia (2002).

5. V. Bhakoo and Sohal, AAn Assessment into the Drivers of E-Business Adoption within the Australian Pharmaceutical Supply Chain, 39th Annual Meeting of the Decision Sciences Institute at Baltimore, Maryland, USA, 22-25 November (2008). 
6. K. Sweeny The Pharmaceutical Industry in Australia, Pharmaceutical Industry Project Working Paper Series No. 34, Centre for Strategic Economic Studies, Victoria University of Technology, Australia (2007).

7. Medicare Australia Medicare Australia Annual Report 2007-2008, Canberra, Australia (2009).

8. C. Lin and Pervan, G. The Practice of IS/IT Benefits Management in Large Australian Organizations, Information \& Management, 41(1), 13-24 (2003).

9. C. Lin, Huang, Y., and Jalleh, G. Improving Alliance Satisfaction: The Resource Alignment of IT Competency in Small Healthcare Centers, International Technology Management Review, November, 1(2), 2542 (2008).

10. C. Lin, Huang, Y. and Burn, J. Realising B2B eCommerce Benefits: The Link with IT Maturity, Evaluation Practices, \& B2B e-Commerce Adoption Readiness, European Journal of Information Systems, 16(6), 806-819 (2007).

11. B. Farbey, Land, F., and Targett, D. Evaluating investments in IT. Journal of Information Technology, 7, 109-122 (1992).

12. M. M. Yusof, Papazafeiropoulou, A., Paul, R. J., and Stergioulas, L. K. Investigating Evaluation Frameworks for Health Information Systems, International Journal of Medical Informatics, 77, 377-385 (2008).

13. C. Lin, Pervan, G., and McDermid, D. IS/IT Investment Evaluation and Benefits Realization Issues in Australia, Journal of Research and Practices in Information Technology, 37(3), 235-251 (2005).

14. C. Lin, Huang, Y., Cheng, M., and Lin, W. Effects of Information Technology Maturity on the Adoption of Investment Evaluation Methodologies: A Survey of Large Australian Organizations, International Journal of Management, 24(4), 697-711 (2007b).

15. C. Lin, Lin, K., Huang, Y., and Jalleh, G. The Fit Between Organizational B2B E-commerce Policy, IT Maturity and Evaluation Practices on B2B Ecommerce Performance in Australian Healthcare Organizations, African Journal of Business Management, 5(4), 1983-2005 (2011).

16. C. Lin, Huang, Y., Jalleh, G., Liu, Y., and Tung, M. An Exploratory Study of Factors Affecting Adoption and Implementation of B2B E-Commerce in Australian Health Care Organizations, International Journal of Electronic Commerce Studies, 1(2), 77-96 (2010).

17. B. Hochstrasser Justifying IT Investments. In L. Willcocks (Ed.), Information Management: The Evaluation of Information Systems Investments (Ch 8, pp. 151-169). Chapman and Hall, London (1994).

18. C. Lin, Huang, Y. and Stockdale, R. Developing a
B2B Website Effectiveness Model for SMEs, Internet Research, 21(3), 304 - 325 (2011).

19. V. Serafeimidis, and Smithson, S. Information Systems Evaluation as an Organisational Institution Experience from a Case Study, Information Systems Journal, 13(2), 251-274 (2003).

20. K. Lin, Lin, C. and Tsao, H. IS/IT Investment Evaluation and Benefit Realization Practices in Taiwanese SMEs, Journal of Information Science and Technology, 2(4), pp. 44-71 (2005).

21. C. Lin, and Huang, Y. Key Factors Affecting the B2B E-Commerce Evaluation and Outsourcing Practices in Australian and Taiwanese Hospitals, International Technology Management Review, 3(1), 22-41 (2013).

22. C. Standing, and Lin, C. Organizational Evaluation of the Benefits, Constraints \& Satisfaction with Business-To-Business Electronic Commerce, International Journal of Electronic Commerce, 11(3), 107-153 (2007).

23. M. M. Parker, Benson, R. J. and Trainor, H. E. Information Economics: Linking Business Performance to Information Technology. New Jersey, Prentice-Hall (1988).

24. J. Ward, and Griffiths, P. Strategic Planning For Information Systems, John Wiley and Sons Ltd, Chichester, UK (1996).

25. C. Lin, and Huang, Y. A Model of IT Evaluation Management: Organizational Characteristics, IT Evaluation Methodologies, and B2BEC Benefits, Lecture Notes in Computer Science, 149-158 (2007).

26. C. Lin, and Huang, Y. An Integrated Framework for Managing eCRM Evaluation Process, International Journal of Electronic Business, 5(4), 340-359 (2007).

27. C. Lin, Pervan, G. and McDermid, D. Issues and Recommendations in Evaluating and Managing the Benefits of Public Sector IS/IT Outsourcing, Information Technology and People, 20(2), 161-183 (2007).

28. K. K. Kim and Umanath, N. S. Information Transfer in B2B Procurement: An Empirical Analysis \& Measurement, Information \& Management, 42(6), 813-828 (2005).

29. K. M. Eisenhardt, K. M. Building Theories From Case Study Research, Academy of Management Review, 14(4), 532-550 (1989).

30. D. Silverman Interpreting qualitative data (2nd ed.). London: Sage (2001).

31. M. B. Miles and Huberman, A.M. Qualitative Data Analysis: An Expanded Sourcebook, Sage Publications, California (1994).

32. R. K. Yin Case Study Research, Design \& Methods, 3rd Ed., Newbury Park, USA, (2002).

Published by Atlantis Press

Copyright: the authors 
33. P. Weill The Role and Value of Information Technology Infrastructure: Some Empirical Observations. In R. Banker, R. Kauffman and M.A. Mahmood (Eds.), Strategic Information Technology Management: Perspectives on Organizational Growth and Competitive Advantage. Middleton, PA: Idea Group Publishing (1993).

34. W.T. Lin and Shao, B.B.M. The Relationship Between User Participation \& System Success: A Simultaneous Contingency Approach, Information \& Management, 37, 283-295 (2000). 